J. clin. Path. (1949), 2, 129.

\title{
THE VALUE OF DILUTED ANTIGEN IN THE WASSERMANN REACTION

\author{
BY
}

\author{
R. F. JENNISON, J. B. PENFOLD, AND J. A. FRASER ROBERTS
}

\begin{abstract}
From the Pathology Laboratory, Essex County Hospital, and Research Department, Royal Eastern Counties Institution, Colchester
\end{abstract}

(RECEIVED FOR PUBliCATION, NOVEMBER 19, 1948)

This paper reports an attempt to assess the value of a modification of the Wassermann reaction wherein a suitable dilution of the normal antigen together with an increased amount of serum was used in an additional tube as suggested by Richardson (1940). By this method we hoped, first, to be able to differentiate specific reactions in sera giving doubtful results with the standard Wassermann technique from non-specific reactions, and, secondly, to detect weakly positive sera in cases of treated syphilis.

Sordelli (1931), by using two strengths of lipoidal emulsion as antigen in combination with two strengths of serum, showed that the specificity of the Wassermann reaction could be greatly increased. Richardson (1940) adapted the WylerHarrison technique accordingly and improved the specificity of the Wassermann reaction in doubtful cases and at the same time maintained the sensitivity as compared with the standard WylerHarrison technique.

Vaughan (1947) recently published results agreeing with those of Richardson and found that both the specificity and sensitivity were increased by the new method. Both Richardson and Vaughan compared the standard Wassermann reaction with the modified technique whereas we have used this method as a verification test for doubtful sera and as a more sensitive test for weakly positive sera.

The theoretical basis of the modified test as suggested by Richardson is as follows. There is abundant excess of specific hapten present in the lipoid extract ; therefore with weakly reacting sera the excess of specific hapten in the usual antigen (1:15 dilution of the lipoid extract) might produce zonal inhibition which would be overcome by using a diluted antigen (1:90 to $1: 150$ dilution of the lipoid extract). Combining proportions of antigen and antibody would thereby be nearer the optimum. Further, at such high dilutions the strength of any contaminating non-specific hapten or haptens should be too low to fix a full dose of complement. So, by using the usual antigen in one tube and in another the antigen diluted $1: 6$ to $1: 10$, the specific and non-specific reactions should be more easily distinguished.- A specific reaction which is partly suppressed by zone inhibition with the usual antigen should be enhanced with the diluted antigen where proportions are nearer the optimum, whereas a non-specific reaction which is partial with the usual antigen should be weakened with the diluted antigen, provided that any contaminating hapten is not present in sufficient strength to fix a full complement dose when the antigen is diluted.

\section{Technique}

The Wassermann Reaction.-The technique used for the routine test was that described by Panton and Marrack (1945). To this we added tube 4, which contained diluted antigen and increased serum. The full test is summarized in Table $I$.

TABLE I •

SUMMARY OF WASSERMANN TEST

\begin{tabular}{c|c|c|c|c|c}
\hline Tube & $\begin{array}{c}\text { Serum } \\
\text { (ml.) }\end{array}$ & $\begin{array}{c}\text { Saline } \\
\text { (ml.) }\end{array}$ & $\begin{array}{c}\text { Comple- } \\
\text { ment } \\
(3 \text { M.H.D. } \\
\text { in } 0.5 \text { ml. })\end{array}$ & $\begin{array}{c}\text { Antigen } \\
(\mathrm{ml})\end{array}$ & $\begin{array}{c}\text { Sensi- } \\
\text { tized } \\
\text { cells } \\
\text { (ml.) }\end{array}$ \\
\hline 1 & 0.1 & 0.4 & 0.5 & 0.5 & 1.0 \\
2 & 0.1 & 0.2 & 0.7 & 0.5 & 1.0 \\
3 & 0.2 & 0.8 & 0.5 & 0 & 1.0 \\
$\left(\begin{array}{c}\text { Control) } \\
4\end{array}\right.$ & 0.2 & 0.3 & 0.5 & 0.5 & 1.0 \\
& & & & (diluted) & \\
\hline
\end{tabular}


Sera.-The sera were heated at $56^{\circ} \mathrm{C}$. for half an hour just before the test.

Antigen.-The antigen was that described by Panton and Marrack (1945), but in tube 4 it was diluted 1 in 7 with normal saline. This was the dilution found by titration to be the most satisfactory. for the batch of antigen used.

Control Tube.-When tube 4 was not in use, tube 3 contained $0.1 \mathrm{ml}$. of serum and $0.9 \mathrm{ml}$. of saline, but as $0.2 \mathrm{ml}$. of the serum were used in tube 4 the control tube had to contain a similar amount with $0.8 \mathrm{ml}$. of saline to cover any anticomplementary action in tube 4.

Sensitized Cells.-The sensitized cells were an equal mixture of 5 per cent sheep red blood cells and 0.5 per cent haemolytic serum (B.W.) in normal saline.

Incubation.-The tests were incubated at $37^{\circ} \mathrm{C}$. for 45 minutes at the fixation stage, and after the addition of the cells for a further 20 minutes at $37^{\circ} \mathrm{C}$.

The Kahn Reaction.-All sera were tested at the same time by the standard Kahn reaction.

Reading of the Tests.-The Kahn tests were read as positive, negative, or doubtful. The Wassermann reactions were read similarly ; that is, in the absence of complete fixation or complete haemolysis in all test tubes the result was doubtful. After the tests were read dilutions from the control tubes which represented 100 per cent haemolysis were made with water in four similar tubes to give standards of $20,40,60$, and 80 per cent haemolysis (that is, 80, 60, 40, and 20 per cent of fixation). All tubes not showing complete haemolysis were centrifuged and the supernatant was compared with the five standard tubes. The degree of haemolysis in tubes 1,2 , and 4 of all tests was thereby estimated to the nearest 10 per cent and recorded.

\section{Selection and Classification of Cases}

During the investigation approximately 9,000 routine standard Wassermann and Kahn reactions were carried out. The sera came from venereal disease and antenatal clinics and from general cases. During the latter part of the investigation we ceased to do the Wassermann and standard Kahn reactions on the antenatal cases as a routine, but instead used a presumptive Kahn reaction as a screening test. Sera with doubtful or positive Kahn reactions were also received from other laboratories in the region which did not undertake Wassermann reactions.

From these routine cases we selected for the modified test: (1) those sera showing incomplete fixation with 3 M.H.D. of complement ; (2) those sera showing a discrepancy between the routine Wassermann and Kahn reaction; (3) sera from cases of treated syphilis which previously had not been consistently negative with the modified test; (4) sera from cases giving positive routine Wasser- mann or Kahn reactions with no clinical evidence $\frac{0}{\vec{\sigma}}$ of syphilis; and (5) sera from antenatal clinics giving a positive or doubtful presumptive $\mathrm{Kahn} \stackrel{\text { 号 }}{\vec{F}}$ reaction.

These cases were classified as follows: group.. , untreated syphilis; group II, treated syphilis ; $\overline{\overline{0}}$ group III, cases suspected of syphilis from theळ history or clinical signs; and group IV, cases without history or signs of syphilis.

The total number investigated was one thousand. $\overrightarrow{0}$

If no tube 4 had been used our Wassermann $=$ reaction results would have been as shown in ${ }_{\sigma}^{\omega}$ Table II.

TABLE II

RESULTS OF THE WASSERMANN REACTION BY THE STANDARD TECHNIQUंE

\begin{tabular}{|c|c|c|c|c|c|c|c|}
\hline \multirow[b]{2}{*}{ Group } & \multirow{2}{*}{$\begin{array}{c}\text { No. } \\
\text { of } \\
\text { sera }\end{array}$} & \multicolumn{3}{|c|}{ Numbers } & \multicolumn{3}{|c|}{ Percentages } \\
\hline & & $\begin{array}{l}\text { Posi- } \\
\text { tive }\end{array}$ & $\begin{array}{c}\text { Doubt- } \\
\text { ful }\end{array}$ & $\begin{array}{l}\text { Nega- } \\
\text { tive }\end{array}$ & $\begin{array}{l}\text { Posi- } \\
\text { tive }\end{array}$ & $\begin{array}{c}\text { Doubt- } \\
\text { ful }\end{array}$ & $\begin{array}{c}\text { Nega } \\
\text { tive }\end{array}$ \\
\hline $\begin{array}{c}\text { I } \\
\text { III } \\
\text { IV }\end{array}$ & $\begin{array}{r}68 \\
531 \\
140 \\
261\end{array}$ & $\begin{array}{r}44 \\
95 \\
20 \\
3\end{array}$ & $\begin{array}{r}13 \\
137 \\
23 \\
19\end{array}$ & $\begin{array}{r}11 \\
299 \\
97 \\
239\end{array}$ & $\begin{array}{r}65 \\
18 \\
14 \\
1\end{array}$ & $\begin{array}{r}19 \\
26 \\
17 \\
7\end{array}$ & $\begin{array}{l}16 \\
56 \\
69 \\
92\end{array}$ \\
\hline
\end{tabular}

It was expected that positive results would occur $\frac{}{2}$ with decreasing frequency in our clinical groups $\mathbf{I}_{\vec{F}}$ to IV, and, as Table II shows, our belief was amply? confirmed. When the negative results by the standard technique-i.e., showing complete haemolysis: in tubes 1 and 2-were considered in the light of haemolysis or fixation in tube 4 it was found that? some were confirmed by complete haemolysis in tube 4 and others were made doubtful by the presence of complete or partial fixation in that tube (see Table III).

TABLE III

NEGATIVE RESULTS (100 PER CENT HAEMOLYSIS IN TUBES 1 을. AND 2)

\begin{tabular}{|c|c|c|c|c|}
\hline Group & $\begin{array}{l}\text { Total } \\
\text { tests }\end{array}$ & $\begin{array}{l}\text { Confirmed } \\
\text { by tube } 4\end{array}$ & $\begin{array}{c}\text { Made } \\
\text { doubtful } \\
\text { by tube } 4\end{array}$ & $\begin{array}{c}\text { Percentage } \\
\text { made } \\
\text { doubtful }\end{array}$ \\
\hline$\underset{\text { III }}{\text { II }}$ & $\begin{array}{r}11 \\
299 \\
97 \\
239\end{array}$ & $\begin{array}{r}5 \\
216 \\
88 \\
237\end{array}$ & $\begin{array}{r}6 \\
83 \\
9 \\
2\end{array}$ & $\begin{array}{r}54.5 \\
27.8 \\
9.3 \\
0.8\end{array}$ \\
\hline
\end{tabular}

This shows that of 646 sera which would have्D been negative with the standard Wassermann reaction technique, 100 became doubtful by the 
modified technique. As 89 of these are known syphilitic cases and nine probably or possibly syphilitic, there is an obvious increase in sensitivity.

Turning now to the doubtful results by the standard technique and assessing them with the results in tube 4 , they are more clearly seen if , those showing fixation in tube 4 equal to or greater than in tube 1 are grouped together, and those with fixation in tube 4 less than in tube 1 kept separate.

TABLE IV

DOUBTFUL RESULTS (PARTIAL FIXATION IN TUBES 1 AND 2)

\begin{tabular}{|c|c|c|c|c|c|}
\hline \multirow{2}{*}{ Group } & \multirow{2}{*}{$\begin{array}{l}\text { No. } \\
\text { of sera }\end{array}$} & \multicolumn{2}{|c|}{ Fixation } & \multicolumn{2}{|c|}{ Percentages } \\
\hline & & $4 \geqslant 1$ & $4<1$ & $4 \geqslant 1$ & $4<1$ \\
\hline$\underset{\text { IV }}{\text { II }}$ & $\begin{array}{r}13 \\
137 \\
23 \\
19\end{array}$ & $\begin{array}{r}13 \\
111 \\
14 \\
3\end{array}$ & $\begin{array}{r}0 \\
26 \\
9 \\
16\end{array}$ & $\begin{array}{r}100 \\
81 \\
61 \\
16\end{array}$ & $\begin{array}{r}0 \\
19 \\
39 \\
84\end{array}$ \\
\hline
\end{tabular}

It is clear that fixation is less in tube 4 than in tube 1 , with increasing frequency from group 1 to group IV, and suggests that this fact is helpful in differentiating between those irregular results due to syphilis from those which are not, thereby increasing the specificity of the test. In only five cases was the standard Wassermann positive (that is, full fixation in tubes 1 and 2) converted to doubtful by the presence of tube 4 (partial fixation in that tube). In all, the fixation in this tube was high-namely, 80 per cent, 80 per cent, 70 per cent, 60 per cent, 60 per cent. The significance of these results is discussed later. It is evident that the addition of tube 4, and the use of this reading in accordance with theoretical expectation, improves the specificity and sensitivity of the Wassermann reaction.

In order to combine the haemolysis readings so as best to separate probably positive from probably negative results, it is necessary to examine the figures without preconceptions. The statistical methods used are described more fully elsewhere (Jennison, Penfold, and Roberts, 1948); in the present paper we are presenting briefly the results obtained. The material comprises the readings in the three tubes for the 297 cases in which haemolysis is incomplete in at least one tube. The problem is to find that method of using the readings which maximizes the variation between the four clinical groups, and at the same time mini mizing the variation within the groups; in othe: words, what is required is to combine the percentage haemolysis readings so as to make the four clinical groups as unlike as possible. The measure of the efficiency attained is the ratio of the variation between groups to the variation within groups; this is called the variance ratio.

It was found that the percentage haemolysis figures in tubes 1 and 2 were, when taken alone, of no value for classifying doubtful sera, for the variation within groups actually exceeds the variation between groups. (This is an interesting confirmation of the sound but not always accepted practice that the standard Wassermann reaction should not be read otherwise than as positive, doubtful, and negative.) The readings in tube 4, however, gave a very different result. The variance ratio is no less than 12.10 , indicating a very useful amount of discrimination. This is illustrated graphically in Fig. 1, which shows that the

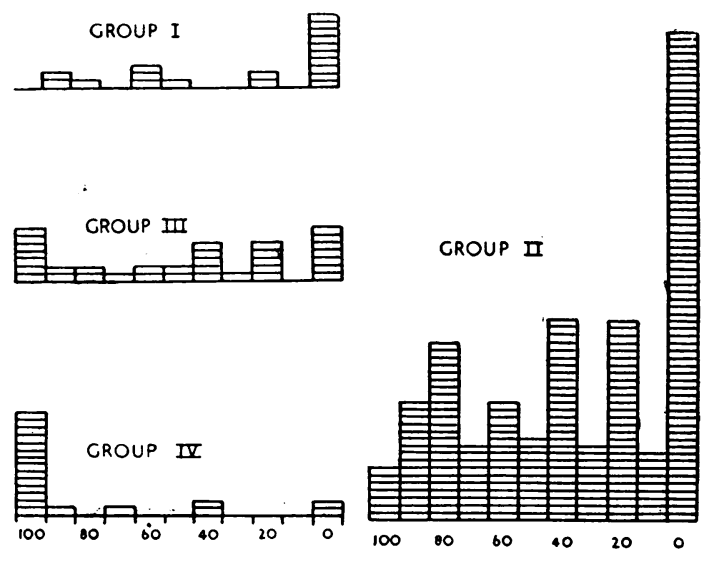

FIG. 1

less haemolysis there is in tube 4 the more likely the result is to be truly positive (using, as always, the criterion that the four clinical groups represent decreasing proportions of true sero-positive syphilis). Actually the reading in tube 4 alone differentiates the groups somewhat better than does the difference between tubes 1 and 4 , the method suggested by theory. This latter method gives a variance ratio of 10.67 . The discrimination attained is illustrated by Fig. 2 .

The next task was to combine the readings in all the tubes in such a way as to maximize the difference between groups. The function which does so is the following:

$105+(\%$ haemolysis in tube 1$)-\frac{1}{2}(\%$ haemolysis in tube 2$)-1 \frac{1}{2}(\%$ haemolysis in tube 4$)$. 


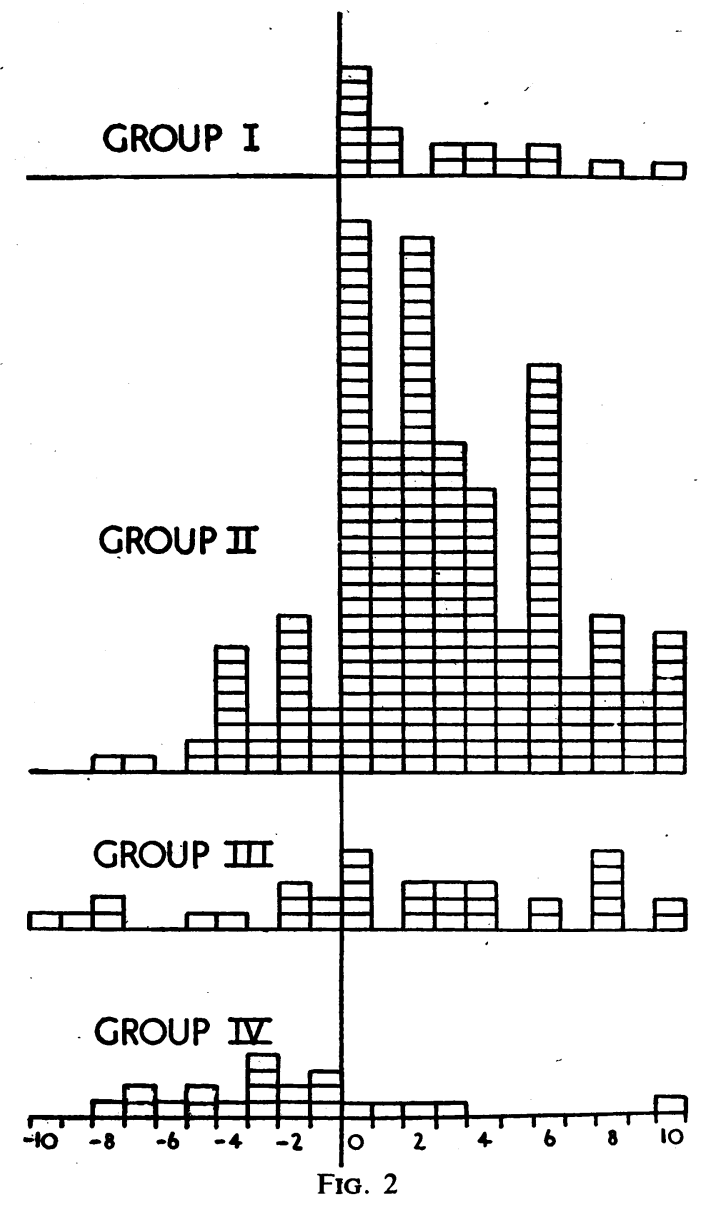

The variance ratio is now 16.77 -that is, the variation between the four clinical groups is $\mathbf{1 6 . 7 7}$ times the variation within the groups.

TABLE $V$

COMPARISON OF EFFICIENCY OF DIFFERENT PROCEDURES

\begin{tabular}{l|c|c}
\hline & $\begin{array}{c}\text { Variance } \\
\text { ratio }\end{array}$ & $\begin{array}{c}\text { Relative } \\
\text { efficiency }\end{array}$ \\
\hline Discriminant function & 16.77 & 100 \\
Reading in tube 4 alone & 12.10 & 72 \\
Differencè tube 4-tube 1 & 10.67 & 64 \\
Tubes 1 and 2 alone .. & $<1$ & - \\
\hline
\end{tabular}

The rounding off of the coefficients of the function to $1, \frac{1}{2}$, and $1 \frac{1}{2}$ entails only a trifling loss of information and has the great advantage of giving a formula that can be worked out in a moment. The arbitrary constant, 105, has been chosen so that if a positive answer (including zero) is regarded as "probably positive" and a negative answer aš "probably negative" as many group II as possible. are made probably positive without making mores than five of group IV probably positive. The diso crimination attained is illustrated in Fig. 3.

The result is a remarkable one. Although per $\frac{\sqrt{5}}{\sqrt{5}}$ centage haemolysis in tubes 1 and 2 is useless by itself for further discrimination of doubtful seray yet in combination these readings are capable of improving considerably the result obtained from? tube 4 alone. Furthermore the function confirms $\vec{s}$ theoretical expectation, for its leading feature in the difference between tube 1 and tube 4 . Its. greater efficiency compared with the simple differ ence method is due to assigning greater weight tơ tube 4, to taking into account the magnitude of the difference, and also to making some lesser use of tube 2. Actually, the increased efficiency attained by using the discriminant function is not fully shown by the comparison of the variance ratios because of the limited range of values when read $\leq$ ings are made in steps of 10 per cent.

It will be noted that as in the difference method (tube 1 -tube 4) a previously negative result mado doubtful by tube 4 becomes probably positive, bus unlike the difference method, the function makes the five previously full positives probably positive In all the fixation in tube 4 was high (80 per cent ${ }_{\Omega}$ 80 per cent, 70 per cent, 60 per cent, 60 per cent); it would have to be 20 per cent or less to make such a result " probably negative." As three of these cases belonged to group II and two to group III this would appear to be an additional. advantage of the function.

A comparison of the difference method and the discriminant function method is shown in Table $\mathrm{VI}_{\mathrm{O}}^{-}$.

\section{TABLE VI}

COMPARISON OF THE DISCRIMINANT FUNCTION AND SIMPLD DIFFERENCES WITH 297 DOUBTFUL SERA

\begin{tabular}{|c|c|c|c|c|}
\hline \multirow{2}{*}{ Group } & \multicolumn{2}{|c|}{ Probably positive } & \multicolumn{2}{|c|}{ Probably negative } \\
\hline & Function & Difference & Function & Difference \\
\hline$\underset{\text { III }}{\text { II }}$ & $\begin{array}{r}19 \\
212 \\
27 \\
5\end{array}$ & $\begin{array}{r}19 \\
194 \\
23 \\
5\end{array}$ & $\begin{array}{r}0 \\
11 \\
7 \\
16\end{array}$ & $\begin{array}{r}0 \\
29 \\
11 \\
16\end{array}$ \\
\hline
\end{tabular}

The figures under "Difference" are obtaine by adding $4>1$ and $4=1$ for the "probably posi $\mathbb{R}$ tive" and $4<1$ for the "probably negative." $\mathbb{\mathbb { D }}$

The actual magnitude of the figure given by the function with individual sera should not be inter- 


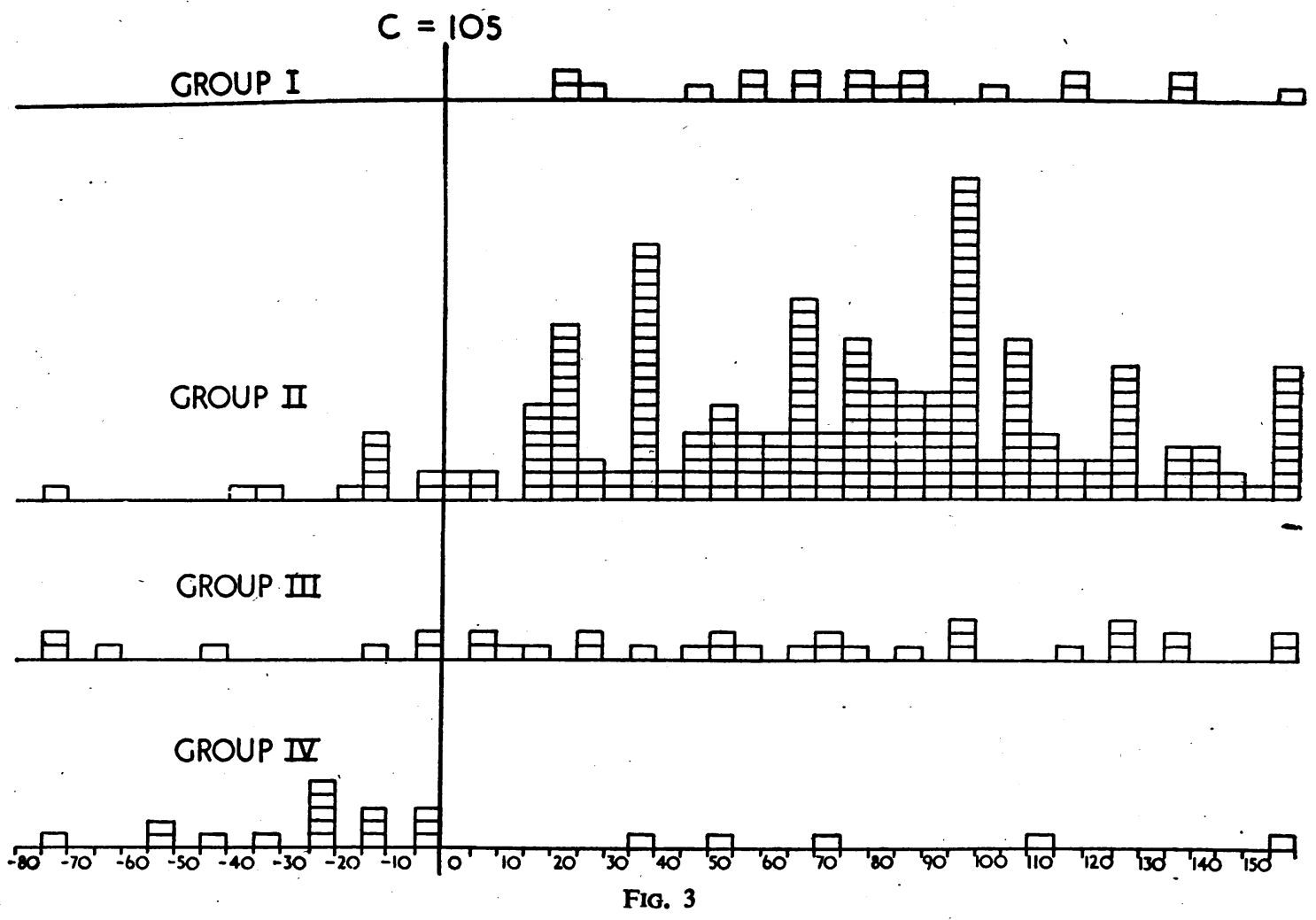

preted too closely ; that is to say, while it may be true in a rough general way that the larger the figure the "more positive" the result and vice versa, there will be many anomalies. This is due to the very non-normal distribution of the haemolysis figures. In spite of this a straightforward linear function of the variables is obviously useful, and a more complex function might well prove no more satisfactory, and would be both difficult and tedious to apply in practice. It is clear that common sense must be used with the results obtained, caution observed in arguing from actual figures, and results near the borderline read with some degree of reserve.

No attempt to assess the value and position of the standard Kahn reaction was undertaken. This has already been done many times. However, in terms of simple product-moment correlation coefficients, using three categories, positive, doubtful, and negative, the correlation of the Kahn test with the various tubes was as follows:

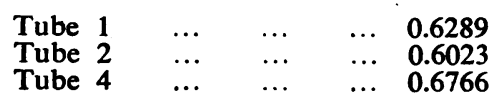

The closer correspondence of tube 4 with the Kahn is not very marked, but the difference is significant.

\section{Summary}

One thousand Wassermann and Kahn tests were performed on sera expected to give difficult results. The sera were separated into four groups according to the clinical diagnosis. The standard Kahn test was used, but the Wassermann was modified by the addition of an extra tube (tube 4 ) in which was increased serum and decreased antigen. The addition of this tube to the test increased its specificity and sensitivity. A discriminant function was worked out and used with the results to aid their interpretation. Its value has been shown and it is simple to use. The Kahn test correlated most closely with the additional tube.

\section{REFERENCES}

Jennison, R. F., Penfold, J. B., and Roberts, J. A. F. (1948). Brit. J. soc. Med., 2, 139.

Panton, P. N., and Marrack, J. R. (1945). "Clinical Pathology." London, p. 180.

Richardson, G. M. (1940). Brit. J. vener. Dis., 16, 166.

Sordelli, A. League of Nations Publications III. Health 1931. III, 4 (no. C.H. 968).

Vaughan, A. C. T. (1947). Brit. J. vener. Dis., 23, 77. 